\title{
Endoscopic transnasal approach for removing pituitary tumors
}

\author{
Acesso transnasal endoscópico para remoção de tumores da hipófise \\ Mirian Cabral Moreira de Castro', Luciane Maria Pereira Michel', Mariana Moreira de Castro Denaro ${ }^{7}$ \\ Pollyana Anício Magalhaes Gontijo ${ }^{1,3}$, Atos Alves de Sousa ${ }^{3}$
}

\begin{abstract}
To describe a series of 129 consecutive patients submitted to the resection of pituitary tumors using the endoscopic transsphenoidal approach in a public medical center. Method: Retrospective analysis based on the records of patients submitted to the resection of a pituitary tumor through the endoscopic transsphenoidal approach between 2004 and 2009. Results: One hundred and twenty-nine records were analyzed. The tumor was non-secreting in 96 (74.42\%) and secreting in 33 patients (22.58\%). Out of the secretory tumors, the most prevalent was the growth hormone producer (7.65\%), followed by the prolactinoma, (6.98\%). Eleven patients developed cerebral spinal fluid (CSF) fistulas, and four of them developed meningitis. One patient died due to intracerebral hemorrhage in the postoperative period. Conclusion: The endoscopic transsphenoidal approach to sellar tumors proved to be safe when the majority of the tumors were nonsecreting. The most frequent complication was CSF. This technique can be done even in a public hospital with financial limits, since the health professionals are integrated.
\end{abstract}

Keywords: pituitary neoplasms, cerebrospinal fluid, fistula, sphenoid sinus.

RESUMO

Descrever uma série de 129 pacientes submetidos à ressecção de tumor de hipófise com acesso endoscópico transesfenoidal em um serviço de público referência em Belo Horizonte. Método: Análise retrospectiva realizada por análise dos prontuários de pacientes submetidos à ressecção de tumor de hipófise com acesso endoscópico transesfenoidal entre os anos 2004 e 2009. Resultados: Foram avaliados 129 prontuários. 0 tumor era não secretante em 96 (74,42\%) e secretante em 33 pacientes (22,58\%). Dos tumores secretores, o de maior prevalência foi o produtor de hormônio do crescimento: 15 pacientes (7,65\%). Onze pacientes desenvolveram fístula liquórica. Um paciente faleceu devido hemorragia intracerebral no pós-operatório. Conclusão: 0 acesso endoscópico transfenoidal aos tumores selares mostrou-se seguro numa população em que a maioria dos tumores era não secretante. A principal complicação encontrada foi fístula liquórica. Esta técnica é passível de utilização em hospital público mesmo com limites financeiros desde que haja integração multiprofissional.

Palavras-chave: neoplasias hipofisárias, líquido cefalorraquidiano, fistula, seio esfenoidal.

Transnasal approaches to the sella turcica have been used since 1910 when the incision in the gingivolabial groove associated with the transseptal approach was introduced. Subsequently, the sublabial incision was combined with the septal submucous incision, preserving the nasal function and avoiding scarring ${ }^{1}$. The use of intraoperative fluoroscopy and microscope in the 1960s represented an important advance, replacing craniotomy and reducing the rate of surgical mortality to less than two percent. The transseptal approach associated with the use of the microscope remained the gold standard of the transsphenoidal approach for more than 30 years and is still the preferred method in some centers ${ }^{2}$.

The popularization of endoscopic sinus surgery took place in the 1970s and, in 1992, Jankowski described the first successful surgical cases using the endoscopic transsphenoidal approach to the hypophysis ${ }^{3}$. This is the less traumatic route to the sella turcica, avoiding brain retraction, and also permitting good visualization, with lower rates of morbidity and mortality when compared to the transcranial route,

\footnotetext{
1Departamento de Otorrinolaringologia, Hospital da Santa Casa de Belo Horizonte, Belo Horizonte MG, Brazil;

${ }^{2}$ Departamento de Otorrinolaringologia, Hospital das Clínicas, Belo Horizonte MG, Brazil;

${ }^{3}$ Departamento de Neurocirurgia, Hospital da Santa Casa de Belo Horizonte, Belo Horizonte MG, Brazil.

Correspondence: Pollyana Anício Magalhães Gontijo; Av Francisco Sales 111 Santa Efigênia; 301520-221 Belo Horizonte MG, Brasil;

E-mail: pollyanaam@hotmail.com

Conflict of interest: There is no conflict of interest to declare.

Received 01 August 2013; Received in final form 18 February 2014; Accepted 10 March 2014.
} 
besides faster postoperative recovery ${ }^{4}$. It also avoids the use of the nasal speculum and postoperative tamponade ${ }^{5}$.

The use of the endoscope is particularly useful in cases of recurrence in patients previously operated through the sublabial or transseptal submucous approach as the dissection of the scar tissue becomes unnecessary, allowing direct approach to the target. In cases of postoperative cerebrospinal fluid (CSF) fistulas, endoscopy allows direct visualization of the location of the fistula and its correction'.

The use of the endonasal endoscopic approach has progressively expanded, including the treatment of various supra and parasellar lesions such as craniopharyngiomas, meningiomas, Rathke's cleft cyst, clivus chordoma, and lesions of the cavernous sinus. When compared to the techniques that utilize microscopes, endoscopic surgery permits a wider field of vision, better visualization of the supra and parasellar region and of the neurovascular structures (optic nerves, chiasm, carotid artery, and cavernous sinus). The introduction of the endoscope in the sella turcica brings to sight the structures and the normal tissue/tumor interface thus facilitating the removal of tumor remains. The lateral field of vision is wider, the limitation on movement created by the use of the speculum is avoided ${ }^{7}$, there is no need for the detachment of the nasal septum, and, accordingly, there is less damage to the nasal physiology and a reduction of morbidity when compared to other techniques ${ }^{5}$.

Following the premise of minimally invasive techniques, the endoscopic transsphenoidal approach has been used in the surgical treatment of tumors of the hypophysis since 2004 in a medical reference center in Belo Horizonte. Such sellar and parasellar tumors include a diverse group of lesions that affect nine in every 10,000 people. Pituitary adenomas account for more than $90 \%$ of the intrasellar tumors and are the most common cause of pituitary disease in adults ${ }^{8}$. They account for 10 to $15 \%$ of all the intracranial tumors and, approximately, one in every 10,000 individuals are diagnosed yearly with pituitary adenoma ${ }^{9}$. They are more common in women aged 30 to 50 years old. Adenomas are divided into secretory and non-secretory. The non-secretory and the prolactinomas are the more frequent and correspond to up to $2 / 3$ of the pituitary tumors. In addition to prolactin, they can produce corticotropin, growth hormone (GH) or of a mixed nature. They can also be classified by size into microadenomas $(<1 \mathrm{~cm})$ and macroadenomas $(>1 \mathrm{~cm})$.

The clinical manifestations include symptoms arising out of excessive hormonal production (acromegaly or giantism Cushing's syndrome and galactorrhea-amenorrhea) and symptoms arising out of the compression of neurovascular structures (visual disorders and cephalea or headache). The preferred treatment is surgical removal, except for the prolactinomas that respond very well to medication. Surgery presents good rates of disease control and very low morbidity and mortality. Stereotactic radiotherapy and radiosurgery are indicated in selected cases (recurrence and patients whose clinical condition does not permit surgery) ${ }^{10}$.

A lot of studies ${ }^{4,6,7,10}$ have demonstrated the superiority of endoscopic transsphenoidal surgery over microsurgery for sellar lesions. The objective of this study is to describe 129 consecutive cases of patients operated between 2004 and 2009 in a well-known medical reference center in the city of Belo Horizonte. These relevant series show the possibility of performing this modern technique in a large public hospital with over a thousand beds just using the resources of the public health system and a multi-professional team.

\section{METHOD}

This is a retrospective study based on the analyses of the records of patients submitted to the resection of pituitary tumors by means of the endoscopic transsphenoidal approach between 2004 and 2009. Preoperative exams included computerized tomography (CT), magnetic resonance imaging (MRI), evaluation of the visual field and visual acuity, and endocrinological evaluation to determine the presence of secreting tumors or hormonal deficiency. Postoperative follow-up included imaging (CT and MRI) and evaluation by the neurosurgeon otorhinolaryngologist, endocrinologist and ophthalmologist.

It is important to emphasize that all the patients were operated by the neurosurgeon conjointly with the otorhinolaryngologist.

The studied patients submitted to the resection of pituitary tumors were classified by age, sex, and hospitalization period. Regarding the type of tumor, they were divided into non-secreting and secreting and, and also according to type of hormone produced.

The research project was approved by the Ethics Committee in Research of Hospital da Santa Casa de Belo Horizonte, under number 059/2010.

\section{RESULTS}

Between 2004 and 2009, 129 patients, 48 men (37.20\%) and 81 women (62.80\%), with hypophysial tumors were operated through the endoscopic transsphenoidal approach.

Age average was 39 years, ranging from 12 to 70 years. In every patient, surgery was aimed at the total removal of the tumor. Postoperative follow-up varied between four and 189 months, with an average of 19 months. Hospitalization average time was four days, varying between three and 22 days.

In 96 patients $(74.42 \%)$, the tumor was non-secreting and secreting in the other 33 patients (25.58\%). The most prevalent secreting tumor was the producer of GH, in 15 patients $(7.65 \%)$, followed by prolactinoma, in nine patients 
(6.98\%), and adrenocorticotropic hormone (ACTH), in eight patients (6.20\%). The least common secreting tumor was the producer of thyrotrophic hormone (TSH), in only one case $(0.78 \%)$. This data is in Table 1.

The main complication was CSF fistulas, that occurred in 11 patients $(8.5 \%)$ and was cured by conservative treatment in seven cases (5.53\%), and four of those patients (3.1\%) were reoperated through the endoscopic approach to close the fistula. Meningitis occurred in four $(3.1 \%)$ patients, with good evolution through antibiotics therapy. One patient died due to major intracerebral hemorrhage in the postoperative period. Table 2 presents the complications described.

\section{DISCUSSION}

The endoscopic transsphenoidal bi-nasal approach, through the two nostrils, was used in all the procedures in this series and there was no relevant intraoperative bleeding that made it necessary to interrupt the surgical procedure, Nevertheless, in the literature some reports of this nature can be found, in which bleeding due to injury of the internal carotid artery during the surgery led to its interruption ${ }^{11}$.

One problem that has been associated to the endoscopic technique is the constant need for cleaning the optical system. However, new equipment has been developed allowing a malleable suction and irrigation device to be coupled to the endoscope, making bimanual surgery possible. On the other hand, this adaptation does not let the suction device to be freely moved, apart from the endoscope, and that extremely important in cases of intense bleeding ${ }^{12}$.

Another possibility variation to solve this problem is the use of endoscope holders, a mechanical device to fix the endoscope, placed after the opening of the sphenoid sinus. This way, the surgeon has the two hands free to perform the procedure ${ }^{6,5,11}$. But some surgeons prefer not to use endoscope holders ${ }^{13,14}$, as the ones in the present series, because one of the greatest advantages of the endoscope is its mobility, allowing rapid change of positioning as need arises. The surgery carried out jointly by the neurosurgeon and the ear, nose and throat (ENT) team permits the ENT

Table 1. Types of tumors observed in this series of patients.

\begin{tabular}{lcc}
\hline Type of tumor & N & $\%$ \\
\hline Non-secreting tumors & 96 & $74.42 \%$ \\
Secreting tumors & & \\
GH producers & 15 & $11.62 \%$ \\
Prolactinomas & 09 & $6.98 \%$ \\
ACTH producers & 08 & $6.20 \%$ \\
TSH producers & 01 & $0.78 \%$ \\
Total & 129 & $100.00 \%$ \\
\hline GH: Growth hormone; ACTH: & Adrenocorticotropic hormone; TSH: \\
Thyrotrophic hormone & &
\end{tabular}

to make the approach and then manipulate the endoscope in one of the nostrils, allowing the neurosurgeon to use both hands to resect the tumor through the other nostril. Another drawback related to the use of holders is that one of the means to obtain a notion of depth, lost because of the bidimensional vision of the endoscope, is moving it forwards and backwards, utilizing fixed points of the anatomy of the nasal cavity as reference points. A fixed endoscope does not allow this maneuver ${ }^{5}$.

The exploration of the sellar region with an angled endoscope, after the removal of the tumor, is carried out routinely. This inspection is fundamental for identifying and removing tumor remains and for finding and correcting lesions of the sellar diaphragm, which can result in CSF leakage. The $45^{\circ}$ endoscope is introduced into the sella turcica, and rotated $360^{\circ}$, inspecting the supra, para, and retrosellar region, and the floor of the sella. In a recent study, the exploration of the sellar region with angled endoscope was undertaken in 13 patients, after removal of tumors with surgical microscopy. In seven of them, tumor remains that had not been visible to the microscopy were found ${ }^{15}$.

In the present series, there was a predominance of female patients and the majority of the tumors were classified as non-functioning, corroborating the results found in the literature ${ }^{16,17}$.

Endoscopic surgery, performed by experienced hands, is quite safe, well-tolerated by patients, and hospitalization time is shorter when compared to conventional surgery $^{18,19,20}$. In the present series, average hospitalization period was four days, varying between three and 22 days, which is very similar to other series described by others authors: some with an average of 4.1 days (first group of 15 cases), 4.5 days (second group of 15 cases), and 2.4 days (third group of 15 cases) 21; and others with an average hospitalization period of 3.36 days in their first 100 cases operated by the endoscopic transnasal approach; in comparison, a series of 100 patients operated by the sublabial approach presents an average hospitalization period of 6.35 days $^{11}$.

The low rate of complications depends on several factors such as the extension of the tumoral resection, the type of tumor, and the preservation of the structures around the injury (hypophysis, cavernous sinus, suprasellar space). The visual control offered by the endoscope contributed to the reduction of the complications in the literature ${ }^{22}$, because the majority of serious complications in sinonasal endoscopic surgeries (such as drilling of the ethmoid roof, lesions of the optic nerve) were related to poor visibility conditions due to excessive bleeding ${ }^{23}$. In our series, a low rate of complications was also observed, the main being CSF fistula (see Table 2), as in other studies ${ }^{3,13,14,16,17,18,21,24,25}$.

Among the authors that refer to the number of CSF leaks occurring in the intraoperational phase, the figures vary a lot: $15.55 \%^{21} ; 14.28 \%^{26} ; 14.11 \%^{25} ; 12 \%^{24} ; 4.44 \%^{21}$; and $2.30 \%^{25}$. The 
Table 2. Complications in this series.

\begin{tabular}{lcc}
\hline Type of complication & $\mathrm{N}$ & $\%$ \\
\hline CSF Fistula & & \\
$\quad$ Reoperated & 04 & $03.10 \%$ \\
$\quad$ Conservative treatment & 07 & $05.43 \%$ \\
Meninigitis & 04 & $03.10 \%$ \\
Death & 01 & $0.78 \%$ \\
No complications & 113 & $87.59 \%$ \\
Total & 129 & $100 \%$ \\
\hline CSF: Cerebrospinal fluid. & &
\end{tabular}

endonasal endoscopic approach is at present the preferred approach for the treatment of such cases that are not cured by conservative treatment, accounting for the success in over $90 \%$ in the first surgery as reported in the literature ${ }^{27}$.

In the present series, meningitis occurred in $3.10 \%$ of the patients, with good evolution after antibiotic therapy, similar to results found by other authors: $2.22 \%^{27}$ and $2.00 \%{ }^{24}$. Other complications described in the literature are intrasellar hematoma (rare), hypopituitarism $(<1 \%)$, diabetes insipidus (0.4$3 \%)$. However, such complications of endocrinological nature have not been reported in this work as it is intended to discuss only the endoscopic approach to the pituitary tumors.

No nasal complaints were observed in the present series. In the literature, nasal complications such as septal drilling, synechia, and abscesses are significantly lower when compared to the microsurgical transseptal or sublabial approach ${ }^{28,29}$.

The success rate in the removal of pituitary tumors through the endoscopic transnasal approach is comparable to or higher than that of the microsurgical technique, reaching more than $95 \%$ of total removal id $n$ cases of adenomas ${ }^{7,30}$.

In summary, the series were found to be higher than in most of the studies reviewed ${ }^{6,7,12,15,16,17,19,20,24,26,30,31}$. The clinical application to this find is that the insertion of this modern technique slightly invasive should be encouraged once they can be performed in large hospitals funded by the public health system and operated by a integrated multiprofessional team.

In conclusion, the endoscopic transsphenoidal approach to sellar tumors can be performed in a minimally invasive way, and the nasal structures were preserved in all the patients. The main complication found in this study was CSF fistula. In the majority of these cases, the conservative treatment reached good results and only four were surgically treated. All of them presented no major complications. The introduction of this modern technique in public hospitals is feasible and should be encouraged. The interdisciplinary approach is essential.

\section{References}

1. Couldwell WT. Transsphenoidal and transcranial surgery for pituitary adenomas. J Neurooncol 2004;69:237-256.

2. Landolt AM. History of pituitary surgery from the technical aspect. Neurosurgery Clinical New American 2001;12:37-44

3. Jankowski R, Auque J, Simon C. Endoscopic pituitary tumor surgery. Laryngoscope 1992;102:198-202.

4. Divitiis E. Endoscopic transsphenoidal surgery: stone in the pond effect. Neurosurgery 2006;59:512-520.

5. Divitiis E, Cappabianca P. Endoscopic endonasal transsphenoidal surgery. In: Pickard JD (Ed). Advances and technical standards in neurosurgery. New York, Springer-Verlag, 2002:137-177.

6. Cappabianca P, Alfieri A, Colao A, et al. Endoscopic endonasal transsphenoidal surgery in recurrent and residual pituitary adenomas: Technical note. Min Invas Neurosurg 2000;43:38-43.

7. Charalampaki P, Reisch P, Ayad A, et al. Endoscopic endonasal pituitary surgery: Surgical and outcome analysis of 50 cases. J Clin Neurosc 2007;14:410-415.

8. Jagannathan J, Kanter AS, Sheehan JP, Jane JA Jr, Laws ER Jr. Benign brain tumors: sellar/parasellar tumors. Neurology Clin 2007;25:1231-1249

9. Davis JR, Farrell WE, Clayton RN. Pituitary tumours. Reproduction 2001:121:363-71.

10. Mortini P, Losa M, Barzaghi R, Boari N, Giovanelli M. Results of transsphenoidal surgery in a large series of patients with pituitary adenoma. Neurosurgery 2005;56:1222-33.
11. Van Lindert EJ, Grotenhuis JA. New endoscope shaft for endoscopic transsphenoidal pituitary surgery. Neurosurgery 2005;57(Suppl 1):S203-S206.

12. Cappabianca P, Cavallo LM, Colao A, de Divitiis E. Surgical complications associated with the endoscopic endonasal transsphenoidal approach for pituitary adenomas. J Neurosurg 2002;97:293-298.

13. Stamm AC, Bordasch A, Vellutini E, Pahl F. Transnasal endoscopic surgery of sellar and parasellar Regions. In: Stamm AC, Draf W (Eds). Micro-endoscopic surgery of the paranasal sinuses and the skull base. Berlim: Springer Verlag; 2000:555-567.

14. Baussart B, Aghakhani N, Portier F, Chanson P, Tadie M, Parker F. Endoscope-assisted microsurgery for invasive endo- and suprasellar pituitary macroadenomas: a consecutive retrospective study with 13 patients. Neurochirurgie 2005;51:455-463.

15. Sonnenburg RE, White D, Ewend MG, Senior B. The learning curve in minimally invasive pituitary surgery. Am J Rhinol 2004;18:259-263.

16. Graham SM, Iseli TA, Karnell LH, Clinger JD, Hitchon PW, Greenlee JD. Endoscopy approach for pituitary surgery improves rhinologic outcomes. Ann Otol Rhinol Laryngol 2009;118:630-635.

17. Gondim JA, Schops M, de Almeida JP, et al. Endoscopy endonasal transsphenoidal surgery: surgical results of 228 pituitary adenomas treated in a pituitary center. Pituitary 2010;13:68-77.

18. D'Haens J, Van Rompaey K, Stadnik T, Haentjens P, Poppe K, Velkeniers B. Fully endoscopic transsphenoidal surgery for functioning pituitary adenomas $\mathrm{A}$ retrospective comparison with traditionao transsphenoidal microsurgery in the same institution. Surg Neurol 2009;72:336-340. 
19. Higgins TS, Courtemanche C, Karakla D, et al. Analysis of transnasal endoscopic versus transseptal microscopic approach for excision of pituitary tumors. Am J Rhinol 2008;22:649-652.

20. Charalampaki P, Ayad A, Kockro RA, Perneczky A. Surgical complications after endoscopic transsphenoidal pituitary surgery. J Clin Nuerosc 2009;16:786-789.

21. Sethi DS, Leong JL. Endoscopic pituitary surgery. Otolaryngol Clin North Am 2006;39:563-583.

22. Santos RP. Complicações das cirurgias endoscópicas nasossinusais. Rev Bras Cirurg Cabeça Pescoço 2003;31:27-30.

23. White DR, Sonnenburg RE, Ewend MG, Senior BA. Safety of minimally invasive pituitary surgery (MIPS) compared with a traditional approach. Laryngoscope 2004;114:1945-1948.

24. Cappabianca P, Cavallo LM, Esposito F, Valente V, De Divitiis E. Sellar repair in endoscopic endonasal transsphenoidal surgery: results of 170 cases. Neurosurgery 2002;51:1365-1371.
25. Aust MR, McCaffrey TV, Atkinson J. Transnasal endoscopic approach to the sella turcica. Am J Rhinol 1998;12:283-287.

26. Silva LR, Santos RP, Zymberg ST. Endoscopic endonasal approach for cerebrospinal fluid fistulae. Mini Invas Neurosurg 2006;49:88-92.

27. Rosen MR, Saigal K, Evans J, Keane WM. A review of the endoscopic approach to the pituitary through the sphenoid sinus. Curr Opin Otolaryngol Head Neck Surg 2006;14:6-13.

28. Senior BA, Ebert CS, Bednarski KK, et al. Minimally invasive pituitary surgery. Laryngoscope 2008;118:1842-1855.

29. Enseñat J, Quesada JL, Aparicio J, et al. Comparacion del abordaje sublabial transesfenoidal microquirurgico frente al abordaje endonasal tranesfenoidal endoscopico. Estudio prospectivo de 50 pacientes. Neurocirurgia 2009;20:335-345.

30. Petry C, Leães CGS, Pereire-Lima JPS, Gerhardt KD, Sant GD, Oliveira MC. Complicações oronasais em pacientes pós-abordagem hipofisária via transesfenoidal. Braz J Otorhinolaryngol 2009;75:345-349. 